\title{
REVIEW
}

\section{Bench-to-bedside review: Hypercapnic acidosis in lung injury - from 'permissive' to 'therapeutic'}

\author{
Marloes M ljland*, Leo M Heunks and Johannes G van der Hoeven
}

\begin{abstract}
Modern ventilation strategies for patients with acute lung injury and acute respiratory distress syndrome frequently result in hypercapnic acidosis (HCA), which is regarded as an acceptable side effect ('permissive hypercapnia'). Multiple experimental studies have demonstrated advantageous effects of HCA in several lung injury models. To date, however, human trials studying the effect of carbon dioxide per se on outcome in patients with lung injury have not been performed. While significant concerns regarding HCA remain, in particular the possible unfavorable effects on bacterial killing and the inhibition of pulmonary epithelial wound repair, the potential for HCA in attenuating lung injury is promising. The underlying mechanisms by which HCA exerts its protective effects are complex, but dampening of the inflammatory response seems to play a pivotal role. After briefly summarizing the physiological effects of HCA, a critical analysis of the available evidence on the potential beneficial effects of therapeutic HCA from in vitro, ex vivo and in vivo lung injury models and from human studies will be reviewed. In addition, the potential concerns in the clinical setting will be outlined.
\end{abstract}

\section{Introduction}

Worldwide, acute lung injury (ALI) and acute respiratory distress syndrome (ARDS) are associated with a high mortality rate (35 to $45 \%$ ) [1]. Modern ventilation strategies include the use of low tidal volumes and/or limiting plateau pressure and have been shown to reduce morbidity and mortality in patients with ALI and ARDS [2-4]. The subsequent increase in arterial carbon dioxide tension $\left(\mathrm{PaCO}_{2}\right)$ is regarded as an acceptable side-effect ('permissive hypercapnia'). In current practice, mean

${ }^{*}$ Correspondence: M.ijland@ic.umcn.nl

Department of Intensive Care Medicine, Radboud University Nijmegen Medical Centre, Geert Grooteplein 10,6500 HB Nijmegen, The Netherlands maximum $\mathrm{PaCO}_{2}$ and $\mathrm{pH}$ associated with permissive hypercapnia are around $8.9 \mathrm{kPa}$ and 7.2 , respectively [2], and are reported to be well tolerated as long as tissue perfusion and oxygenation are preserved and there are no contraindications [5-7]. Numerous studies have investigated the effects of hypercapnic acidosis (HCA) in laboratory animals and humans; to date, however, it is unclear whether HCA should be considered as an acceptable adverse effect of lung-protective ventilation or as therapeutic by itself ('therapeutic hypercapnia'). Human trials studying the effect of carbon dioxide $\left(\mathrm{CO}_{2}\right)$ per se on outcome in patients with lung injury have not been carried out to date. After briefly summarizing the physiological effects of HCA, we present a critical analysis of the available evidence on the potential beneficial effects of therapeutic HCA from in vitro, ex vivo and in vivo lung injury models and from human studies.

\section{Physiological effects of hypercapnic acidosis}

HCA has a myriad of effects on many physiological processes. The recognition of these effects is important as it will affect the decision whether or not to allow the development of HCA in a specific patient. As outlined below, the final effect of HCA on physiological functions depends on the level of hypercapnia, the context of the subject (healthy versus diseased) and many other factors. Therefore, we will briefly review the physiological effects of HCA.

\section{Oxygenation}

The beneficial effects of HCA in increasing arterial and tissue oxygenation is evident from multiple in vivo studies [8-16] and has been demonstrated in healthy humans as well [17]. HCA can improve tissue oxygenation by several mechanisms. First, a rightward shift of the oxyhemoglobin dissociation curve during acute respiratory acidosis decreases the affinity of hemoglobin for oxygen and facilitates oxygen release to the tissues (the Bohr effect) [18]. Second, HCA causes vasodilatation in microvessels, promoting oxygen delivery and tissue perfusion. However, high concentrations of $\mathrm{PCO}_{2}$ $(>13.3 \mathrm{kPa})$ will surpass the beneficial vasodilatory effects of HCA and result in vasoconstriction [19]. Third, HCA 
improves ventilation-perfusion (V/Q) matching by potentiating hypoxic pulmonary vasoconstriction $[15,16]$. In contrast, impaired V/Q matching has been demonstrated with HCA in patients with ARDS [20,21]. The differences in V/Q matching in these studies could be explained by the manner in which hypercapnia was achieved - inhaled $\mathrm{CO}_{2}[15,16]$ versus low-volume (pressure-limited) ventilation-induced hypercapnia. In the latter case, atelectasis may develop, leading to increased intrapulmonary shunting [20,21]. As inhaled $\mathrm{CO}_{2}$ theoretically results in a more uniform lung acidosis, it might be superior to low minute ventilation-induced hypercapnia in achieving improved V/Q matching and an anti-inflammatory effect, as has been suggested by Sinclair and colleagues [22]. Fourth, as cardiac output is one of the major determinants of peripheral oxygen delivery, one can expect that a $\mathrm{CO}_{2}$-mediated increase in cardiac output augments peripheral oxygen delivery. However, an increase in cardiac output results in an increase in mixed venous oxygen tension which may lead to an increase in pulmonary shunting due to attenuation of hypoxic pulmonary vasoconstriction $[21,23]$.

\section{The lung}

\section{Pulmonary compliance}

As will be outlined below, it has been demonstrated in experimental studies that pulmonary compliance is improved by HCA. This may be explained by the $\mathrm{pH}-$ mediated effect of HCA in improving surfactant secretion and its surface-tension-lowering properties $[24,25]$.

\section{Pulmonary vascular tone}

Increases in pulmonary vascular tone may have particularly unfavorable consequences in patients with pulmonary hypertension. Experimental evidence is conflicting concerning the pulmonary vasodilatory or vasoconstrictive effect of HCA [9,26-30]. These apparent opposing effects may be attributable to the presence or absence of $\mathrm{pH}$-buffer resulting in pulmonary vasodilatation or vasoconstriction, respectively $[26,29,30]$.

However, clinical studies demonstrate that HCA causes an increase in mean pulmonary arterial pressure in ARDS [5,31]. Recently, Mekontso and colleagues [32] showed a lower right ventricular stroke index in patients with severe ARDS who were ventilated with higher positive end-expiratory pressure (PEEP; 10 to $11 \mathrm{mmHg}$ ) at a constant plateau pressure that subsequently led to HCA (pH 7.17 to $7.20, \mathrm{PaCO}_{2} 9.44$ to $9.98 \mathrm{kPa}$ ). An increase in pulmonary vascular resistance was postulated but no objective measurements were performed. Multivariate analysis demonstrated that $\mathrm{pH}$, per se, and not $\mathrm{CO}_{2}$ or PEEP, was responsible for the impaired right ventricular function [32]. Therefore, caution is warranted with the use of 'permissive' or 'therapeutic' HCA in patients with pulmonary hypertension and depressed right ventricular function.

\section{Cardiovascular system \\ Cardiac output}

HCA has a direct suppressive effect on cardiac contractility, but it can lead to a net increase in cardiac output by several mechanisms, as has been demonstrated in both animal and human studies [15,17,19,31,33-35]. First, sympathetically mediated release of catecholamines due to neuroadrenal stimulation results in an increase in end-systolic volume and venous return [34,35]. In addition to an increase in heart rate, HCA induces ATPsensitive $\mathrm{K}^{+}$channel-mediated vasodilation, as has been demonstrated for the brain vasculature and coronary vessels [36,37], which could decreases left ventricular afterload. An increase of 1.33 to $1.60 \mathrm{kPa}$ in $\mathrm{PaCO}_{2}$ increases cardiac index by $14 \%$ in the critically ill and healthy mechanically ventilated patient $[17,33]$. In the clinical setting, however, care should be taken with patients exhibiting depressed myocardial function.

\section{Myocardium}

Acidosis has protective effects against myocardial ischemia-reperfusion injury [38,39]. Hydrogen ions inhibit $\mathrm{Ca}^{2+}$ influx into the myocardial fiber, which decreases myocardial contractility and oxygen demand, leading to less tissue injury during myocardial ischemia [39-41]. Furthermore, hypercapnia causes coronary vasodilatation, which may be of further benefit during the period of reperfusion [40]. These protective effects of hypercapnia can be of pivotal importance in the treatment of patients undergoing coronary artery bypass grafting with extracorporeal circulation and subsequently experiencing myocardial suppression.

\section{Central nervous system \\ Cerebral blood flow and tissue oxygenation}

In the absence of intracranial hypertension, HCA may have beneficial effects on the brain. Hypercapnia may improve cerebral blood flow by decreasing cerebrovascular resistance through dilatation of arterioles and improves tissue oxygenation, as has been demonstrated in both human and animal studies [13,42-44]. Consequently, HCA has protective effects against cerebral hypoxic-ischemic injury, as has been demonstrated in rat models $[45,46]$. In a recent clinical study, it was shown that cerebral perfusion changed by $4.0 \mathrm{ml} / 100 \mathrm{~g} /$ minute for each $0.133 \mathrm{kPa}$ change in the partial pressure of $\mathrm{CO}_{2}$ $\left(\mathrm{pCO}_{2}\right)$ [44].

Hypercapnia results in cerebral vasodilatation and a subsequent rise in cerebral blood flow. In the presence of disturbed auto-regulation this can cause critical 
intracranial pressure elevation and reduced cerebral perfusion (reviewed in [6]). Therefore, HCA should be avoided in cases of intracranial pathology, in particular in the absence of intracranial pressure recording.

\section{Effects of hypercapnic acidosis in experimental lung injury \\ Cell culture studies \\ Alveolar macrophages}

Alveolar macrophages play a prominent role in the pathogenesis of ventilator-induced lung injury (VILI), possibly through the generation of cytokines, chemokines, nitric oxide (NO) and free radicals [47-49]. Upon stimulation, alveolar macrophages release proinflammatory cytokines and chemokines, resulting in the activation of polymorphonuclear leucocytes (reviewed in [50]). Activated polymorphonuclear leucocytes increase endothelial and epithelial permeability, resulting in tissue edema and accumulation of high-molecular-weight proteins in the airspaces (reviewed in [50]). HCA decreases cytokine release by alveolar macrophages and this effect appears to be primarily $\mathrm{pH}$-mediated $[51,52]$. For instance, Lang and colleagues [53] demonstrated that $\mathrm{CO}_{2}$ decreased lipopolysaccharide (LPS)-induced TNF- $\alpha$ secretion in rat alveolar macrophages in a dose-dependent fashion. Four hours after exposure to $20 \% \mathrm{CO}_{2}(\mathrm{pH}$ 5.8), TNF- $\alpha$ secretion was only $50 \%$ compared to cells exposed to $2.5 \% \mathrm{CO}_{2}(\mathrm{pH}$ 7.2). However, buffering the culture medium $\mathrm{pH}$ to 7.2 completely abolished the effect of hypercapnia. A decrease in cell metabolic activity appeared to be responsible for the $\mathrm{pH}$-induced decline in cytokine release in these cells as incubation with $20 \%$ $\mathrm{CO}_{2}$ resulted in an approximately $40 \%$ reduction in metabolic activity and an equal reduction in LPSstimulated TNF- $\alpha$ secretion [54].

\section{Alveolar type II epithelial cells}

Hypercapnia has detrimental effects on alveolar type II epithelial cells. For example, in buffered fetal rat type II alveolar epithelial cells, injury is caused by a hypercapniamediated increase in NO, NO synthase and 3-nitrotyrosine leading to protein tyrosine nitration [55]. Additionally, in a scratch injury model where primary type II rat alveolar epithelial cells were injured with a surgical blade, HCA caused more permanent plasma membrane defects and an impaired rate of plasma membrane repair [56]. Recently, O’Toole and colleagues [57] reported impaired pulmonary epithelial wound healing by HCA-induced diminished cellular migration through inhibition of NF- $\mathrm{kB}$. NF- $\mathrm{kB}$ is a transcription factor responsible for the transcription of intercellular adhesion molecule (ICAM)-1 and pro-inflammatory cytokines such as TNF- $\alpha$, IL-1 $\beta$, IL- 6 and IL- 8 (reviewed in $[58,59])$. NF- $\mathrm{KB}$ is present in the cytoplasm in an inactive form through its interaction with inhibitory proteins $\kappa B$ (I $\kappa \mathrm{B})$ and can be activated by multiple stimuli. Regarding the potential for HCA to delay pulmonary epithelial wound repair following mechanical injury, these studies raise concerns regarding epithelial repair in patients with ALI/ARDS undergoing 'permissive' hypercapnia.

\section{Pulmonary artery endothelial cells}

HCA has been demonstrated to inhibit NF-kB in pulmonary artery endothelial cells [60]. In isolated human pulmonary artery endothelial cells, Takeshita and colleagues [60] demonstrated that HCA suppressed ІкB degradation, resulting in reduced NF- $\mathrm{kB}$ activity. This resulted in decreased expression of ICAM-1 and IL-8 with subsequent inhibition of neutrophil adherence (Figure 1). As inflammation plays an important role in the pathogenesis of VILI, this modulating effect of HCA on the inflammatory response may further reduce lung injury during mechanical ventilation associated with hypercapnia.

\section{Experiments in ex vivo lung preparations}

In isolated perfused rabbit lungs it has been demonstrated that $\mathrm{HCA}\left(\mathrm{pH} 6.84, \mathrm{PCO}_{2} 15.96 \mathrm{kPa}\right)$ prevents the development of microvascular permeability by warm ischemia-reperfusion and free-radical-mediated lung injury, possibly via inhibition of endogenous xanthine oxidase [61]. Also, less severe levels of HCA have been shown to attenuate ischemia-reperfusion injury in the isolated rabbit lung [26].

Xanthine oxidase is involved in the metabolism of purines and pyrimidines and generates superoxide and subsequently hydrogen peroxide when oxidizing hypoxanthine or xanthine to uric acid [62]. As various studies have demonstrated a possible role for reactive oxygen species (ROS) in the pathogenesis of ARDS, HCA may offer protection against ROS-mediated lung injury by inhibiting xanthine oxidase $[63,64]$.

Broccard and colleagues [65] have demonstrated a protective role of HCA against reactive nitrogen species (RNS)-mediated lung injury by attenuating the rise in stable end-products of NO metabolism. However, the effects of HCA on RNS are complex. In addition to reducing RNS-mediated injury, HCA can enhance tissue nitration. This has been demonstrated by increased lung nitrotyrosine levels in animals treated with HCA following endotoxin injury and in animals subjected to VILI $[10,66]$. It appears that the net effect of HCA on nitrogen radicals may be beneficial, perhaps because the oxidant pathway is more injurious. More studies are, however, necessary to clearly demonstrate this.

Both ROS and RNS are generated in response to various inflammatory stimuli in lung endothelial, alveolar 


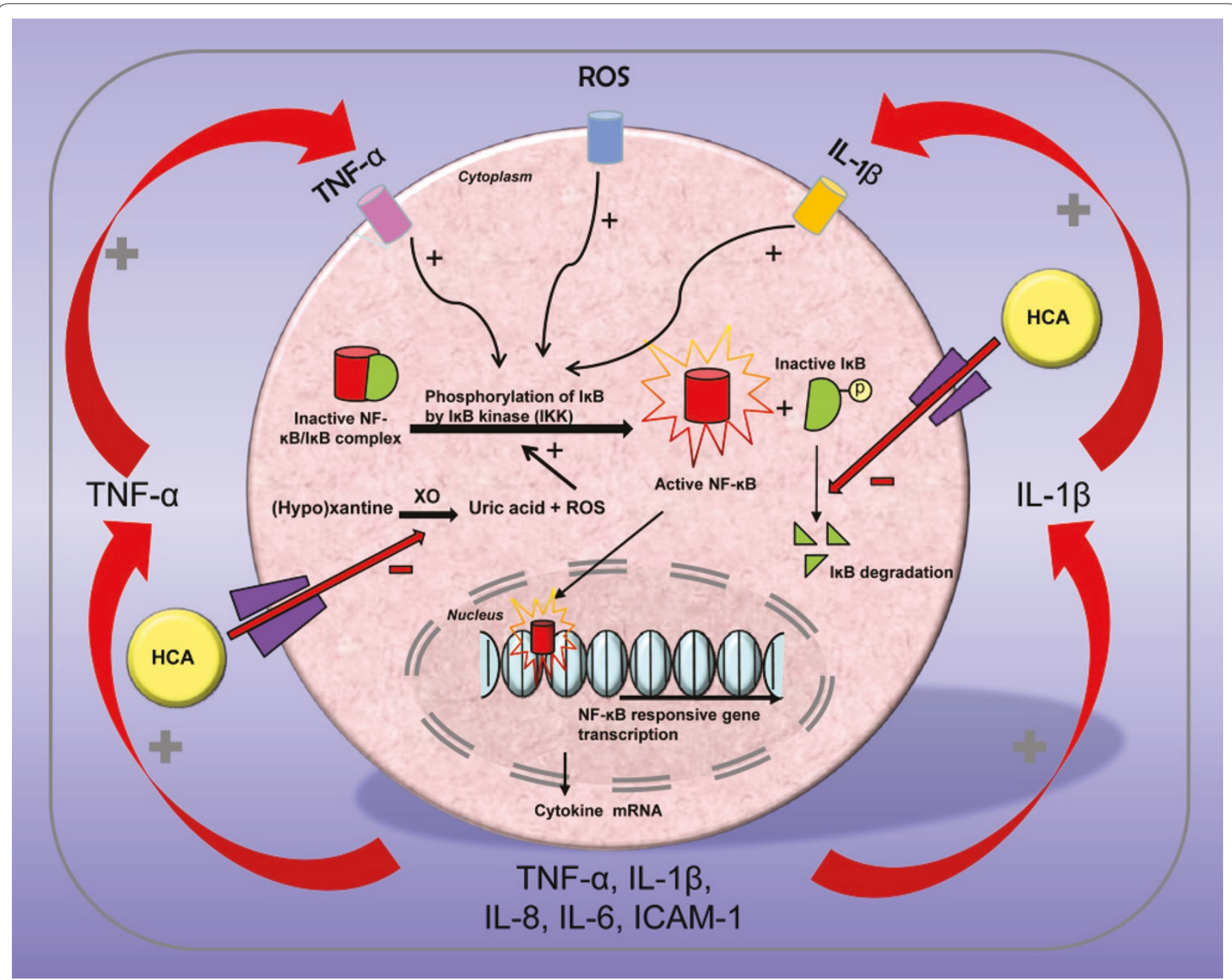

Figure 1. Modulating effect of hypercapnic acidosis on the inflammatory response. NF-KB can be activated by multiple stimuli, such as endotoxin (lipopolysaccharide), reactive oxygen species (ROS) and cytokines (IL-1 $\beta$ and TNF-a). Subsequently, phosphorylation of IKB (inhibitory proteins $\mathrm{KB}$ ) occurs followed by its degradation, allowing NF-KB to be transported to the cell nucleus where it binds to specific promoter sites and activates transcription of target genes. Following activation of NF-kB, both intra- and extracellular feedback mechanism will subsequently regulate NF-kB activation, with IL-1 $\beta$ and TNF-a providing positive extracellular feedback. The potential mechanism by which hypercapnic acidosis (HCA) inhibits NF-KB activation appears to involve suppression of the degradation of 1 KB-a. Subsequently, this will result in suppressed production of IL-1 $\beta$, IL-6, IL-8 and TNF-a. Suppression of intercellular adhesion molecule (ICAM)-1 and IL-8 will subsequently lead to inhibition of neutrophil adherence. HCA may also offer protection against ROS-mediated lung injury by inhibiting xanthine oxidase (XO).

and airway epithelial cells as well as in activated alveolar macrophages and neutrophils [63]. This may result in oxidation, nitration and inactivation of important proteins, DNA and lipids. For example, peroxynitrite can oxidize and nitrate surfactant protein A, resulting in loss of its function $[67,68]$. Alterations in the function, production and composition of surfactant stimulates alveolar collapse with subsequent loss of compliance and deterioration in gas exchange. Impaired surfactant function has been reported in patients with ARDS and may aggravate respiratory failure (reviewed in [69]). As such, HCA may offer protection against lung injury by preventing surfactant nitration [70,71].
Furthermore, it has been demonstrated that HCA increases lamellar body volume density of type II pneumocytes in dog lungs. As lamellar body volume density of type II pneumocytes is known to be associated with intracellular storage and secretion of surfactant, HCA may have a stimulating role on surfactant release [24]. An indirect effect of HCA on surfactant function has also been envisioned. As HCA has been shown to diminish pulmonary microvascular permeability $[26,56,61,70]$, it will prevent elevated bronchoalveolar lavage fluid (BALF) protein concentration, which has been shown to decrease surfactant activity [72]. In the future, in vivo studies are mandatory to investigate the 
specific role of HCA on surfactant in the prevention of lung injury.

\section{In vivo animal studies}

HCA may have protective effects against lung injury as has been shown in multiple in vivo models of lung injury, including ALI induced by bacterial $[12,73]$ or endotoxin instillation [10,74], systemic [9] and pulmonary ischemiareperfusion [70] and stretch-induced lung injury $[8,11,75-77]$, as outlined below.

\section{Bacterial- and endotoxin-induced lung injury}

In an established Escherichia coli-induced lung injury model, $\mathrm{CO}_{2}$ was added 6 hours after E. coli instillation, allowing the development of severe pneumonia. Inspired $\mathrm{CO}_{2}$ attenuated the fall in arterial oxygenation, the increase in peak airway pressure and the reduction in lung compliance. Moreover, histologic lung injury was reduced in the hypercapnic group compared to the normocapnic group in the presence of antibiotic therapy [73]. However, no differences in bacterial loads, BALF neutrophil counts, IL-6 or TNF- $\alpha$ levels were found. These results were confirmed by the same investigators in the setting of evolving pneumonia-induced lung injury [12]. In this study, $\mathrm{CO}_{2}$ was added immediately after E. coli instillation in both neutrophil-depleted and nondepleted rats, suggesting a neutrophil-independent mechanism for the effect of HCA [12].

HCA attenuated endotoxin-induced lung injury in rats as shown by improved arterial oxygenation, reduced alveolar influx of neutrophils and alveolar/tissue edema, reduced NO metabolite concentrations, improved lung compliance and improved histological indices of lung injury when given both prophylactically (before endotoxin instillation) as well as therapeutically (30 minutes after endotoxin instillation) [10]. As ALI is generally well established before the patient comes to the ICU, these data emphasize the potential clinical relevance of HCA. In contrast to these results, an increase in alveolarcapillary membrane permeability, lung wet-to-dry ratio, BALF cell counts, indices of oxidative inflammatory reactions and lung histologic injury were observed with hypercapnia in an intravenous endotoxin-induced ALI rabbit model [74]. Possible explanations for the apparent discrepancies may be differences in plasma $\mathrm{CO}_{2}$ tension $( \pm 9.7 \mathrm{kPa}$ versus $\pm 7.8 \mathrm{kPa}$ ), species used (rat versus rabbit), route of LPS administration (intratracheal versus intravenous) and the method of producing HCA (inhaled $\mathrm{CO}_{2}$ versus low minute ventilation-induced hypercapnia) $[10,74]$.

\section{Ischemia-reperfusion lung injury}

Pulmonary ischemia-reperfusion injury may occur in humans after, for instance, cardiopulmonary bypass, thrombolysis or embolectomy for pulmonary embolism and lung transplantation. In an open chest rabbit model of lung ischemia-reperfusion injury, therapeutic HCA has been demonstrated to exert beneficial effects. Attenuation of the inflammatory response was demonstrated by reduced TNF- $\alpha$ concentration and freeradical-mediated injury [70]. These data are supported by the dose-dependent beneficial effects of HCA on mesenteric ischemia-reperfusion-induced lung injury [9].

\section{Stretch-induced lung injury}

Mechanical ventilation with high tidal volumes or high peak pressure and/or low PEEP causes excessive lung stretch and shear forces, which are considered key determinants of VILI [78,79].

Increased lung compliance, higher arterial partial pressure of oxygen $\left(\mathrm{PaO}_{2}\right)$ and a decrease in lung injury have been demonstrated with HCA in a rabbit VILI model [11]. Stretch-induced lung injury was achieved by subjecting the rabbits to extremely high tidal volume ventilation $(25 \mathrm{ml} / \mathrm{kg})$ and zero PEEP. Although this study suggested that the effect of HCA was independent of tidal volume, it is of limited clinical relevance as both groups were ventilated with these high tidal volumes. However, HCA has demonstrated protective effects at more clinically relevant tidal volumes $[8,75]$, though these effects were less impressive. This supports the theory that lung-protective ventilation strategies reduce VILI to a point that a protective effect of HCA is less detectable.

Recently, we studied the effect of HCA on the immune response by adding $\mathrm{CO}_{2}$ to the inspiratory mixture in a mild VILI model in mice. Indeed, HCA decreased intrapulmonary cytokine levels, leucocyte influx and wet-dry ratio in a dose-dependent fashion [76,80] (Figure 2). These results are in apparent contrast with the findings of a previous study performed in a surfactant-depleted rabbit model [77]. Despite attenuation of BALF monocyte chemoattractant protein-1, no effect of HCA was found on other inflammatory mediators, vascular permeability, lung mechanics or oxygenation. However, an inhaled $\mathrm{CO}_{2}$ concentration of $12 \%$ was used, resulting in extremely high values of $\mathrm{PaCO}_{2}(>18.6 \mathrm{kPa})$ and very low $\mathrm{pH}(<6.9)$, which may have influenced these results. Additionally, as the authors mentioned, the model is prone to atelectasis and HCA may, therefore, be less effective in attenuating lung injury. Furthermore, HCA may improve surfactant production and decrease surfactant surface tension. In this surfactant-depleted rabbit model these beneficial effects of HCA will therefore be absent $[24,25]$.

\section{Human data}

The ARDSnet trial showed that tidal volume ventilation using $6 \mathrm{ml} / \mathrm{kg}$ ideal body weight in patients suffering 


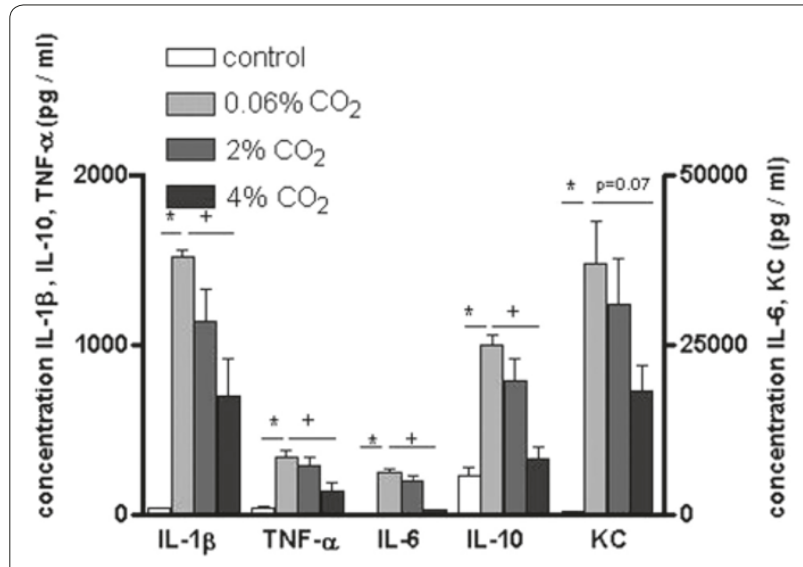

Figure 2. Effect of hypercapnic acidosis on lung tissue cytokines in ventilated mice. Effect of 2 hours of normo- and hypercapnic mechanical ventilation on ventilation-induced lung tissue cytokine release using identical ventilator settings. ${ }^{*} P<0.05$ versus control; $+P<0.05,0.06 \% \mathrm{CO}_{2}$ versus $2 \% \mathrm{CO}_{2}$ versus $4 \% \mathrm{CO}_{2} . \mathrm{KC}$, keratinocytederived chemokine. This figure is reproduced with permission of the publisher. (Halbertsma FJ, Vaneker M, Pickkers P, et al. Hypercapnic acidosis attenuates the pulmonary innate immune response in ventilated healthy mice. Crit Care Med 2008, 36:2403-2406.).

from ALI/ARDS resulted in a significant reduction in mortality of $8.8 \%$ compared to the use of tidal volumes of $12 \mathrm{ml} / \mathrm{kg}$ [3]. Although the $\mathrm{PaCO}_{2}$ was slightly higher in the low tidal volume arm, the effects of HCA could not be separated from lung protective ventilation as an explanation for the decrease in mortality. However, a secondary analysis, using multivariate logistic regression and controlling for co-morbidities and severity of lung injury, demonstrated that HCA on day $1(\mathrm{pH}<7.35$, $\mathrm{PaCO}_{2}>6 \mathrm{kPa}$ ) was associated with reduced mortality in patients ventilated with $12 \mathrm{ml} / \mathrm{kg}$ but not in patients ventilated with $6 \mathrm{ml} / \mathrm{kg}$ [81]. A dose-response relationship between HCA and mortality in this group was demonstrated.

Recently, Terragni and colleagues [82] showed a reduction of tidal hyperinflation and an attenuation of pulmonary inflammation during ventilation with low tidal volumes of $4.2 \pm 0.3 \mathrm{ml} / \mathrm{kg}$ compared to tidal volumes of $6.3 \pm 0.3 \mathrm{ml} / \mathrm{kg}$. The development of HCA was effectively and safely managed by extracorporeal $\mathrm{CO}_{2}$ removal. The question remains if morphological and inflammatory parameters would even be further improved without the use of extracorporeal $\mathrm{CO}_{2}$ removal. To date, however, human trials studying the effect of $\mathrm{CO}_{2}$ per se on outcome in patients with lung injury have not been performed.

In conclusion, based on the experimental data, HCA may have direct protective effects against lung injury as described above. Potential mechanisms responsible for this beneficial effect are complex and probably multifactorial and may be different depending on the cause of lung injury. At least a reduction in inflammatory mediators via the NF-kB pathway, a reduction in RNS and ROS via inhibiting xanthine oxidase and an improvement in surfactant function appear to play an important role in the prevention of lung injury by HCA.

\section{Hypercapnic acidocis versus hypercapnia}

The protective effects of HCA in lung injury models may be a function of $\mathrm{pH}$ or the $\mathrm{CO}_{2}$ per se. This issue is of significant relevance when considering the need for buffering HCA in the clinical context.

The protective effect of HCA in experimental studies (cell culture studies [55], ex vivo studies [26] as well as in in vivo studies [83]) demonstrate that $\mathrm{pH}$ buffering of HCA attenuates its lung protective effect. This suggests that the protective effect of HCA appears to be a function of $\mathrm{pH}$, rather than elevated $\mathrm{CO}_{2}$ per se. However, a synergistic effect between $\mathrm{CO}_{2}$ and $\mathrm{pH}$ may exist, as $\mathrm{HCA}$ seems to be more protective than metabolic acidosis in the setting of ALI [26].

Besides the relevance of the type of acidosis (hypercapnic versus metabolic), the type of buffer (sodium bicarbonate versus tris-hydroxymethyl aminomethane (THAM)) seems to be of particular importance. Despite correcting the arterial $\mathrm{pH}$, administration of sodium bicarbonate has the disadvantage that it may worsen intracellular acidosis. The $\mathrm{CO}_{2}$ generated diffuses rapidly across cell membranes to equilibrate between intracellular and extracellular compartments, leading to intracellular acidosis [84].

Since no human trials have been performed to investigate the effect of buffering during the use of 'therapeutic hypercapnia', no advise about buffering at the bedside can be given.

\section{Other evidence of harm with hypercapnic acidosis Host response to infections}

HCA may attenuate lung injury by reducing neutrophil activity, concentrations of key cytokines, such as TNF- $\alpha$, IL-1 $\beta$, IL- 6 and IL-8, and the expression of ICAM-1 $[10,12,51,52,54,60,70,76,85]$. However, the phagocytic activity and bactericidal capacity of neutrophils and macrophages are essential for an effective host response to invading bacteria. As one of the most common causes of ALI/ARDS remains sepsis [86], concerns have been expressed about the possible deleterious effects of HCA on bacterial killing [87,88]. Recently, Costello and colleagues [89] reported a beneficial effect of HCA in reducing the severity of lung injury in early and prolonged systemic sepsis. Additionally, no effect of HCA on bacterial load was demonstrated, providing some reassurance regarding the safety of HCA in the clinical setting of sepsis. 


\section{Inhibition of phagocytosis}

Various studies have demonstrated an acidosis-mediated suppressant effect on the phagocytic activity of neutrophils and macrophages [90] (reviewed in [91]). Recently, it has been demonstrated that sustained HCA in the presence of prolonged pulmonary infection without antibiotic therapy increases bacterial load and worsens lung injury, mainly through inhibition of neutrophil phagocytosis. However, no difference in lung damage between the normocapnic and HCA group was found with co-administration of antibiotics [92]. This unfavorable effect of HCA is in contrast with other in vivo studies reporting no difference [93] or a modest protective effect of HCA in evolving and established pneumonia-induced lung injury [12,73]. It is also in contrast with the beneficial effects of HCA in the setting of early and prolonged systemic sepsis. This suggests that the effects of HCA appear to depend on the site of infection as well as the stage of infection.

\section{Reduced neutrophil respiratory burst}

An acidosis-mediated suppressant effect on intracellular killing by reduced production of ROS by macrophages and neutrophils has also been demonstrated [90,94] (reviewed in [91]). In human neutrophils, HCA was associated with a pH-dependent decrease in intracellular oxidant production and IL-8 secretion [85].

\section{Neuromuscular system}

Prolonged hypercapnia may have negative effects on the neuromuscular function of the diaphragm. Degenerative changes of the diaphragm were observed after keeping rats in hypercapnic chambers for 6 weeks or more $[95,96]$. These data are of particular importance in the clinical context, where neuromuscular function of the diaphragm plays a pivotal role in the success of weaning from the ventilator.

\section{Milieu interne}

HCA decreases hyperlactatemia in the context of global hypoxemia as well as during normoxia [15,70,97]. Prevention of hyperlactatemia is probably due to a $\mathrm{pH}-$ mediated suppressive effect of HCA on lactic acid generation by decreasing cell metabolism through inhibition of glycolysis (reviewed in [98]). Subsequently, this leads to diminished cellular fuel utilization in times of ischemia. It is reasonable to think that a cellular metabolic shutdown can be beneficial for, for example, the kidney, but it may have unfavorable effects for the brain

\section{Clinical perspective and recommendations}

The protective effect of 'therapeutic' HCA has been demonstrated in various lung injury models $[9,10,12$,
$70,73,74]$. However, caution should be taken when extrapolating these results to the clinical setting. Importantly, the studies performed use different models (that is, levels of hypercapnia, duration and timing of hypercapnia, healthy or injured lungs), with different and sometimes conflicting outcomes that make comparison difficult. Accordingly, the optimal $\mathrm{CO}_{2}$ level for mechanically ventilated patients with ALI is unknown. The concept of an optimal $\mathrm{CO}_{2}$ concentration is essential as most physiological systems are saturable and it is therefore reasonable that an effective upper limit of $\mathrm{CO}_{2}$, a point beyond which advantages shift towards harmful effects, exists.

Despite these uncertainties, the potential for therapeutic hypercapnia in attenuating lung injury is promising. This review supports the need for studying therapeutic $\mathrm{HCA}$ at the bedside in patients without contraindications in a pilot setting. Different methods of eliciting hypercapnia (inhaled $\mathrm{CO}_{2}$ versus low minute ventilation-induced hypercapnia) need further investigation, especially in human studies

\section{Conclusion}

Modern ventilation strategies have demonstrated a reduction in mortality in patients with ALI and ARDS. The subsequent HCA is regarded as an acceptable side effect and is generally well tolerated. Experimental studies have reported a myriad of effects of HCA on many physiological processes. Despite the fact that concerns remain regarding HCA, in particular impaired bacterial killing and the inhibition of pulmonary epithelial wound repair, the potential for therapeutic HCA in attenuating lung injury is promising.

\section{Abbreviations}

ALI, acute lung injury; ARDS, acute respiratory distress syndrome; BALF, bronchoalveolar lavage fluid; $\mathrm{CO}_{2}$ carbon dioxide; $\mathrm{HCA}$, hypercapnic acidosis; ICAM, intercellular adhesion molecule; IKB, inhibitory proteins KB; IL, interleukin; LPS, lipopolysaccharide; NF-KB, nuclear factor kappa B; NO, nitric oxide; $\mathrm{PaCO}_{2}$, arterial carbon dioxide tension; PEEP, positive end-expiratory pressure; RNS, reactive nitrogen species; ROS, reactive oxygen species; TNF, tumor necrosis factor; VILI, ventilator-induced lung injury.

\section{Competing interests}

The authors declare that they have no competing interests.

Published: 3 November 2010

\section{References}

1. Phua J, Badia JR, Adhikari NK, Friedrich JO, Fowler RA, Singh JM, Scales DC, Stather DR, Li A, Jones A, Gattas DJ, Hallett D, Tomlinson G, Stewart TE, Ferguson ND: Has mortality from acute respiratory distress syndrome decreased over time? A systematic review. Am J Respir Crit Care Med 2009, 179:220-227.

2. Hickling KG, Walsh J, Henderson S, Jackson R: Low mortality rate in adult respiratory distress syndrome using low-volume, pressure-limited ventilation with permissive hypercapnia: a prospective study. Crit Care Med 1994, 22:1568-1578.

3. Ventilation with lower tidal volumes as compared with traditional tidal volumes for acute lung injury and the acute respiratory distress syndrome. The Acute Respiratory Distress Syndrome Network. N Engl J Med 2000, 
342:1301-1308

4. Amato MB, Barbas CS, Medeiros DM, Magaldi RB, Schettino GP, Lorenzi-Filho G, Kairalla RA, Deheinzelin D, Munoz C, Oliveira R, Takagaki TY, Carvalho CR: Effect of a protective-ventilation strategy on mortality in the acute respiratory distress syndrome. N Engl J Med 1998, 338:347-354.

5. Thorens JB, Jolliet P, Ritz M, Chevrolet JC: Effects of rapid permissive hypercapnia on hemodynamics, gas exchange, and oxygen transport and consumption during mechanical ventilation for the acute respiratory distress syndrome. Intensive Care Med 1996, 22:182-191.

6. Feihl F, Perret C: Permissive hypercapnia. How permissive should we be? Am J Respir Crit Care Med 1994, 150:1722-1737.

7. Potkin RT, Swenson ER: Resuscitation from severe acute hypercapnia. Determinants of tolerance and survival. Chest 1992, 102:1742-1745.

8. Laffey JG, Engelberts D, Duggan M, Veldhuizen R, Lewis JF, Kavanagh BP: Carbon dioxide attenuates pulmonary impairment resulting from hyperventilation. Crit Care Med 2003, 31:2634-2640.

9. Laffey JG, Jankov RP, Engelberts D, Tanswell AK, Post M, Lindsay T, Mullen JB, Romaschin A, Stephens D, McKerlie C, Kavanagh BP: Effects of therapeutic hypercapnia on mesenteric ischemia-reperfusion injury. Am J Respir Crit Care Med 2003, 168:1383-1390.

10. Laffey JG, Honan D, Hopkins N, Hyvelin JM, Boylan JF, McLoughlin P: Hypercapnic acidosis attenuates endotoxin-induced acute lung injury. Am J Respir Crit Care Med 2004, 169:46-56.

11. Sinclair SE, Kregenow DA, Lamm WJ, Starr IR, Chi EY, Hlastala MP: Hypercapnic acidosis is protective in an in vivo model of ventilator-induced lung injury. Am J Respir Crit Care Med 2002, 166:403-408.

12. Ni Chonghaile M, Higgins BD, Costello JF, Laffey JG: Hypercapnic acidosis attenuates severe acute bacterial pneumonia-induced lung injury by a neutrophil-independent mechanism. Crit Care Med 2008, 36:3135-3144.

13. Hare GM, Kavanagh BP, Mazer CD, Hum KM, Kim SY, Coackley C, Barr A, Baker AJ: Hypercapnia increases cerebral tissue oxygen tension in anesthetized rats. Can J Anaesth 2003, 50:1061-1068.

14. Ratnaraj J, Kabon B, Talcott MR, Sessler DI, Kurz A: Supplemental oxygen and carbon dioxide each increase subcutaneous and intestinal intramural oxygenation. Anesth Analg 2004, 99:207-211.

15. Wang Z, Su F, Bruhn A, Yang X, Vincent JL: Acute hypercapnia improves indices of tissue oxygenation more than dobutamine in septic shock. Am J Respir Crit Care Med 2008, 177:178-183.

16. Swenson ER, Robertson HT, Hlastala MP: Effects of inspired carbon dioxide on ventilation-perfusion matching in normoxia, hypoxia, and hyperoxia. Am J Respir Crit Care Med 1994, 149:1563-1569.

17. Akca O, Doufas AG, Morioka N, Iscoe S, Fisher J, Sessler DI: Hypercapnia improves tissue oxygenation. Anesthesiology 2002, 97:801-806.

18. Turek Z, Kreuzer F: Effect of shifts of the $\mathrm{O} 2$ dissociation curve upon alveolar-arterial $\mathrm{O} 2$ gradients in computer models of the lung with ventilation-perfusion mismatching. Respir Physiol 1981, 45:133-139.

19. Komori M, Takada K, Tomizawa Y, Nishiyama K, Kawamata M, Ozaki M: Permissive range of hypercapnia for improved peripheral microcirculation and cardiac output in rabbits. Crit Care Med 2007, 35:2171-2175.

20. Feihl F, Eckert P, Brimioulle S, Jacobs O, Schaller MD, Melot C, Naeije R: Permissive hypercapnia impairs pulmonary gas exchange in the acute respiratory distress syndrome. Am J Respir Crit Care Med 2000, 162:209-215.

21. Pfeiffer B, Hachenberg T, Wendt M, Marshall B: Mechanical ventilation with permissive hypercapnia increases intrapulmonary shunt in septic and nonseptic patients with acute respiratory distress syndrome. Crit Care Med 2002, 30:285-289

22. Sinclair SE, Kregenow DA, Starr I, Schimmel C, Lamm WJ, Hlastala MP, Swenson ER: Therapeutic hypercapnia and ventilation-perfusion matching in acute lung injury: low minute ventilation vs inspired $\mathrm{CO}_{2}$. Chest 2006, 130:85-92.

23. Hickling KG, Joyce $C$ : Permissive hypercapnia in ARDS and its effect on tissue oxygenation. Acta Anaesthesiol Scand Supp/ 1995, 107:201-208.

24. Shepard JW Jr, Dolan GF, Yu SY: Factors regulating lamellar body volume density of type II pneumocytes in excised dog lungs. J App/ Physio/ 1982, 53:555-562.

25. Wildeboer-Venema F: Influence of nitrogen, oxygen, air and alveolar gas upon surface tension of lung surfactant. Respir Physiol 1984, 58:1-14.

26. Laffey JG, Engelberts D, Kavanagh BP: Buffering hypercapnic acidosis worsens acute lung injury. Am J Respir Crit Care Med 2000, 161:141-146

27. Wexels JC, Mjos OD: Effects of carbon dioxide and $\mathrm{pH}$ on myocardial function in dogs with acute left ventricular failure. Crit Care Med 1987,
$15: 1116-1120$

28. Kantores C, McNamara PJ, Teixeira L, Engelberts D, Murthy P, Kavanagh BP, Jankov RP: Therapeutic hypercapnia prevents chronic hypoxia-induced pulmonary hypertension in the newborn rat. Am J Physiol Lung Cell Mol Physio/ 2006, 291:L912-L922

29. Viles PH, Shepherd JT: Evidence for a dilator action of carbon dioxide on the pulmonary vessels of the cat. Circ Res 1968, 22:325-332

30. Ooi H, Cadogan E, Sweeney M, Howell K, O'Regan RG, McLoughlin P: Chronic hypercapnia inhibits hypoxic pulmonary vascular remodeling. Am J Physiol Heart Circ Physiol 2000, 278:H331-H338.

31. Weber T, Tschernich $H$, Sitzwohl C, Ullrich R, Germann P, Zimpfer M, Sladen RN, Huemer G: Tromethamine buffer modifies the depressant effect of permissive hypercapnia on myocardial contractility in patients with acute respiratory distress syndrome. Am J Respir Crit Care Med 2000, 162:1361-1365.

32. Mekontso DA, Charron C, Devaquet J, Aboab J, Jardin F, Brochard L, VieillardBaron A: Impact of acute hypercapnia and augmented positive endexpiratory pressure on right ventricle function in severe acute respiratory distress syndrome. Intensive Care Med 2009, 35:1850-1858.

33. Mas A, Saura P, Joseph D, Blanch L, Baigorri F, Artigas A, Fernandez R: Effect of acute moderate changes in $\mathrm{PaCO} 2$ on global hemodynamics and gastric perfusion. Crit Care Med 2000, 28:360-365.

34. Walley KR, Lewis TH, Wood LD: Acute respiratory acidosis decreases left ventricular contractility but increases cardiac output in dogs. Circ Res 1990, 67:628-635.

35. Brofman JD, Leff AR, Munoz NM, Kirchhoff C, White SR: Sympathetic secretory response to hypercapnic acidosis in swine. J Appl Physiol 1990, 69:710-717.

36. Nakahata K, Kinoshita H, Hirano Y, Kimoto Y, Iranami H, Hatano Y: Mild hypercapnia induces vasodilation via adenosine triphosphate-sensitive $\mathrm{K}+$ channels in parenchymal microvessels of the rat cerebral cortex. Anesthesiology 2003, 99:1333-1339.

37. Phillis JW, Song D, O'Regan MH: Mechanisms involved in coronary artery dilatation during respiratory acidosis in the isolated perfused rat heart. Basic Res Cardiol 2000, 95:93-97.

38. Kitakaze M, Takashima S, Funaya H, Minamino T, Node K, Shinozaki Y, Mori H, Hori M: Temporary acidosis during reperfusion limits myocardial infarct size in dogs. Am J Physiol 1997, 272:H2071-H2078.

39. Kitakaze M, Weisfeldt ML, Marban E: Acidosis during early reperfusion prevents myocardial stunning in perfused ferret hearts. J Clin Invest 1988, 82:920-927.

40. Nomura F, Aoki M, Forbess JM, Mayer JE Jr: Effects of hypercarbic acidotic reperfusion on recovery of myocardial function after cardioplegic ischemia in neonatal lambs. Circulation 1994, 90:||321-||327.

41. Orchard $\mathrm{CH}$, Kentish JC: Effects of changes of $\mathrm{pH}$ on the contractile function of cardiac muscle. Am J Physiol 1990, 258:C967-C981.

42. Faraci FM, Breese KR, Heistad DD: Cerebral vasodilation during hypercapnia. Role of glibenclamide-sensitive potassium channels and nitric oxide. Stroke 1994, 25:1679-1683.

43. Hino JK, Short BL, Rais-Bahrami K, Seale WR: Cerebral blood flow and metabolism during and after prolonged hypercapnia in newborn lambs. Crit Care Med 2000, 28:3505-3510.

44. Pollock JM, Deibler AR, Whitlow CT, Tan H, Kraft RA, Burdette JH, Maldjian JA: Hypercapnia-induced cerebral hyperperfusion: an underrecognized clinical entity. AJNR Am J Neuroradiol 2009, 30:378-385.

45. Vannucci RC, Towfighi J, Heitjan DF, Brucklacher RM: Carbon dioxide protects the perinatal brain from hypoxic-ischemic damage: an experimental study in the immature rat. Pediatrics 1995, 95:868-874.

46. Vannucci RC, Brucklacher RM, Vannucci SJ: Effect of carbon dioxide on cerebral metabolism during hypoxia-ischemia in the immature rat. Pediatr Res 1997, 42:24-29.

47. Pugin J, Dunn I, Jolliet P, Tassaux D, Magnenat JL, Nicod LP, Chevrolet JC: Activation of human macrophages by mechanical ventilation in vitro. Am J Physiol 1998, 275:L1040-L1050.

48. Eyal FG, Hamm CR, Parker JC: Reduction in alveolar macrophages attenuates acute ventilator induced lung injury in rats. Intensive Care Med 2007, 33:1212-1218.

49. Frank JA, Wray CM, McAuley DF, Schwendener R, Matthay MA: Alveolar macrophages contribute to alveolar barrier dysfunction in ventilatorinduced lung injury. Am J Physiol Lung Cell Mol Physiol 2006, 291:L1191-L1198. 
50. Puneet $\mathrm{P}$, Moochhala $\mathrm{S}$, Bhatia $\mathrm{M}:$ Chemokines in acute respiratory distress syndrome. Am J Physiol Lung Cell Mol Physiol 2005, 288:L3-15.

51. Kos M, Kuebler JF, Jesch NK, Vieten G, Bax NM, van dZ, Busche R, Ure BM Carbon dioxide differentially affects the cytokine release of macrophage subpopulations exclusively via alteration of extracellular $\mathrm{pH}$. Surg Endosc 2006, 20:570-576.

52. Heming TA, Dave SK, Tuazon DM, Chopra AK, Peterson JW, Bidani A: Effects of extracellular $\mathrm{pH}$ on tumour necrosis factor-alpha production by resident alveolar macrophages. Clin Sci (Lond) 2001, 101:267-274.

53. Lang CJ, Dong P, Hosszu EK, Doyle IR: Effect of $\mathrm{CO}_{2}$ on LPS-induced cytokine responses in rat alveolar macrophages. Am J Physiol Lung Cell Mol Physiol 2005, 289:L96-L103.

54. Lang CJ, Barnett EK, Doyle IR: Stretch and $\mathrm{CO} 2$ modulate the inflammatory response of alveolar macrophages through independent changes in metabolic activity. Cytokine 2006, 33:346-351.

55. Lang JD Jr, Chumley P, Eiserich JP, Estevez A, Bamberg T, Adhami A, Crow J, Freeman BA: Hypercapnia induces injury to alveolar epithelial cells via a nitric oxide-dependent pathway. Am J Physiol Lung Cell Mol Physiol 2000, 279:L994-1002.

56. Doerr CH, Gajic O, Berrios JC, Caples S, Abdel M, Lymp JF, Hubmayr RD: Hypercapnic acidosis impairs plasma membrane wound resealing in ventilator-injured lungs. Am J Respir Crit Care Med 2005, 171:1371-1377.

57. O'Toole D, Hassett P, Contreras M, Higgins BD, McKeown ST, McAuley DF, O'Brien T, Laffey JG: Hypercapnic acidosis attenuates pulmonary epithelial wound repair by an NF-kappaB dependent mechanism. Thorax 2009, 64:976-982.

58. Blackwell TS, Christman JW: The role of nuclear factor-kappa B in cytokine gene regulation. Am J Respir Cell Mol Biol 1997, 17:3-9.

59. Tak PP, Firestein GS: NF-kappaB: a key role in inflammatory diseases. J Clin Invest 2001, 107:7-11.

60. Takeshita K, Suzuki Y, Nishio K, Takeuchi O, Toda K, Kudo H, Miyao N, Ishii M, Sato N, Naoki K, Aoki T, Suzuki K, Hiraoka R, Yamaguchi K: Hypercapnic acidosis attenuates endotoxin-induced nuclear factor-[kappa]B activation. Am J Respir Cell Mol Biol 2003, 29:124-132.

61. Shibata K, Cregg N, Engelberts D, Takeuchi A, Fedorko L, Kavanagh BP. Hypercapnic acidosis may attenuate acute lung injury by inhibition of endogenous xanthine oxidase. Am J Respir Crit Care Med 1998, 158:1578-1584.

62. Hille R, Nishino T: Flavoprotein structure and mechanism. 4. Xanthine oxidase and xanthine dehydrogenase. FASEB J 1995, 9:995-1003.

63. Lang JD, MCArdle PJ, O'Reilly PJ, Matalon S: Oxidant-antioxidant balance in acute lung injury. Chest 2002, 122:314S-320S.

64. Brigham KL: Role of free radicals in lung injury. Chest 1986, 89:859-863.

65. Broccard AF, Hotchkiss JR, Vannay C, Markert M, Sauty A, Feihl F, Schaller MD: Protective effects of hypercapnic acidosis on ventilator-induced lung injury. Am J Respir Crit Care Med 2001, 164:802-806.

66. Peltekova V, Engelberts D, Otulakowski G, Uematsu S, Post M, Kavanagh BP: Hypercapnic acidosis in ventilator-induced lung injury. Intensive Care Med 2010, 36:869-878.

67. Zhu S, Haddad IY, Matalon S: Nitration of surfactant protein A (SP-A) tyrosine residues results in decreased mannose binding ability. Arch Biochem Biophys 1996, 333:282-290.

68. Zhu S, Ware LB, Geiser T, Matthay MA, Matalon S: Increased levels of nitrate and surfactant protein a nitration in the pulmonary edema fluid of patients with acute lung injury. Am J Respir Crit Care Med 2001, 163:166-172.

69. Gunther A, Ruppert C, Schmidt R, Markart P, Grimminger F, Walmrath D, Seeger W: Surfactant alteration and replacement in acute respiratory distress syndrome. Respir Res 2001, 2:353-364.

70. Laffey JG, Tanaka M, Engelberts D, Luo X, Yuan S, Tanswell AK, Post M, Lindsay T, Kavanagh BP: Therapeutic hypercapnia reduces pulmonary and systemic injury following in vivo lung reperfusion. Am J Respir Crit Care Med 2000, 162:2287-2294

71. Vesela A, Wilhelm J: The role of carbon dioxide in free radical reactions of the organism. Physiol Res 2002, 51:335-339.

72. Fuchimukai T, Fujiwara T, Takahashi A, Enhorning G: Artificial pulmonary surfactant inhibited by proteins. J App/ Physio/ 1987, 62:429-437.

73. Ni Chonghaile M, Higgins BD, Costello J, Laffey JG: Hypercapnic acidosis attenuates lung injury induced by established bacterial pneumonia. Anesthesiology 2008, 109:837-848.

74. Lang JD, Figueroa M, Sanders KD, Aslan M, Liu Y, Chumley P, Freeman BA: Hypercapnia via reduced rate and tidal volume contributes to lipopolysaccharide-induced lung injury. Am J Respir Crit Care Med 2005, 171:147-157.

75. Strand $\mathrm{M}$, Ikegami $\mathrm{M}$, Jobe $\mathrm{AH}$ : Effects of high $\mathrm{PCO}_{2}$ on ventilated preterm lamb lungs. Pediatr Res 2003, 53:468-472.

76. Halbertsma FJ, Vaneker M, Pickkers P, Snijdelaar DG, van EJ, Scheffer GJ, van der Hoeven HG: Hypercapnic acidosis attenuates the pulmonary innate immune response in ventilated healthy mice. Crit Care Med 2008, 36:2403-2406.

77. Rai S, Engelberts D, Laffey JG, Frevert C, Kajikawa O, Martin TR, Post M, Kavanagh BP: Therapeutic hypercapnia is not protective in the in vivo surfactant-depleted rabbit lung. Pediatr Res 2004, 55:42-49.

78. Dreyfuss D, Saumon G: Ventilator-induced lung injury: lessons from experimental studies. Am J Respir Crit Care Med 1998, 157:294-323.

79. Parker JC, Hernandez LA, Peevy KJ: Mechanisms of ventilator-induced lung injury. Crit Care Med 1993, 21:131-143.

80. Vaneker M, Halbertsma FJ, van EJ, Netea MG, Dijkman HB, Snijdelaar DG, Joosten LA, van der Hoeven JG, Scheffer GJ: Mechanical ventilation in healthy mice induces reversible pulmonary and systemic cytokine elevation with preserved alveolar integrity: an in vivo model using clinical relevant ventilation settings. Anesthesiology 2007, 107:419-426.

81. Kregenow DA, Rubenfeld GD, Hudson LD, Swenson ER: Hypercapnic acidosis and mortality in acute lung injury. Crit Care Med 2006, 34:1-7.

82. Terragni PP, Del SL, Mascia L, Urbino R, Martin EL, Birocco A, Faggiano C, Quintel M, Gattinoni L, Ranieri VM: Tidal volume lower than $6 \mathrm{ml} / \mathrm{kg}$ enhances lung protection: role of extracorporeal carbon dioxide removal. Anesthesiology 2009, 111:826-835.

83. Nichol AD, O'Cronin DF, Howell K, Naughton F, O'Brien S, Boylan J, O'Connor C, O'Toole D, Laffey JG, McLoughlin P: Infection-induced lung injury is worsened after renal buffering of hypercapnic acidosis. Crit Care Med 2009, 37:2953-2961.

84. LiYC, Wiklund L, Tarkkila P, Bjerneroth G: Influence of alkaline buffers on cytoplasmic $\mathrm{pH}$ in myocardial cells exposed to metabolic acidosis. Resuscitation 1996, 32:33-44.

85. Coakley RJ, Taggart C, Greene C, McElvaney NG, O'Neill SJ: Ambient $\mathrm{pCO}_{2}$ modulates intracellular $\mathrm{pH}$, intracellular oxidant generation, and interleukin-8 secretion in human neutrophils. J Leukoc Biol 2002, 71:603-610.

86. Brun-Buisson C, Minelli C, Bertolini G, Brazzi L, Pimentel J, Lewandowski K, Bion J, Romand JA, Villar J, Thorsteinsson A, Damas P, Armaganidis A, Lemaire F: Epidemiology and outcome of acute lung injury in European intensive care units. Results from the ALIVE study. Intensive Care Med 2004, 30:51-61.

87. Swenson ER: Therapeutic hypercapnic acidosis: pushing the envelope. Am J Respir Crit Care Med 2004, 169:8-9.

88. Laffey JG, O'Croinin D, McLoughlin P, Kavanagh BP: Permissive hypercapnia - role in protective lung ventilatory strategies. Intensive Care Med 2004 30:347-356.

89. Costello J, Higgins B, Contreras M, Chonghaile MN, Hassett P, O'Toole D, Laffey $\mathrm{JG}$ : Hypercapnic acidosis attenuates shock and lung injury in early and prolonged systemic sepsis. Crit Care Med 2009, 37:2412-2420.

90. Bidani A, Reisner BS, Haque AK, Wen J, Helmer RE, Tuazon DM, Heming TA: Bactericidal activity of alveolar macrophages is suppressed by V-ATPase inhibition. Lung 2000, 178:91-104.

91. Lardner A: The effects of extracellular pH on immune function. J Leukoc Bio 2001, 69:522-530.

92. O'Croinin DF, Nichol AD, Hopkins N, Boylan J, O'Brien S, O'Connor C, Laffey JG, McLoughlin P: Sustained hypercapnic acidosis during pulmonary infection increases bacterial load and worsens lung injury. Crit Care Med 2008 36:2128-2135.

93. O'Croinin DF, Hopkins NO, Moore MM, Boylan JF, McLoughlin P, Laffey JG: Hypercapnic acidosis does not modulate the severity of bacterial pneumonia-induced lung injury. Crit Care Med 2005, 33:2606-2612.

94. Allen DB, Maguire JJ, Mahdavian M, Wicke C, Marcocci L, Scheuenstuhl H, Chang M, Le AX, Hopf HW, Hunt TK: Wound hypoxia and acidosis limit neutrophil bacterial killing mechanisms. Arch Surg 1997, 132:991-996.

95. Kumagai $\mathrm{M}$, Kondo $\mathrm{T}$, Ohta $\mathrm{Y}$, Ishihara $\mathrm{T}$ : Size and composition changes in diaphragmatic fibers in rats exposed to chronic hypercapnia. Chest 2001, 119:565-571

96. Shiota S, Okada T, Naitoh H, Ochi R, Fukuchi Y: Hypoxia and hypercapnia affect contractile and histological properties of rat diaphragm and hind limb muscles. Pathophysiology 2004, 11:23-30.

97. Abu RS, Tannen RL: Amelioration of hypoxia-induced lactic acidosis by 
superimposed hypercapnea or hydrochloric acid infusion. Am J Physiol 1986, 250:F702-F709.

98. Hood VL, Tannen RL: Protection of acid-base balance by $\mathrm{pH}$ regulation of acid production. N Eng/ J Med 1998, 339:819-826 doi:10.1186/cc9238

Cite this article as: Ijland MM, et al:: Bench-to-bedside review: Hypercapnic acidosis in lung injury - from 'permissive' to 'therapeutic.' Critical Care 2010, $14: 237$ 